\title{
Advantages of the association of resveratrol with oral contraceptives for management of endometriosis-related pain
}

This article was published in the following Dove Press journal:

International Journal of Women's Health

9 October 2012

Number of times this article has been viewed

\author{
Hugo Maia $\mathrm{Jr}^{1,2}$ \\ Clarice Haddad ${ }^{2}$ \\ Nathanael Pinheiro ${ }^{3,4}$ \\ Julio Casoy ${ }^{2}$ \\ 'Itaigara Memorial Day Hospital, \\ ${ }^{2}$ Centro de Pesquisas e Assistência \\ em Reprodução Humana, ${ }^{3}$ ImagePat, \\ Pathology Laboratory, ${ }^{4}$ Department \\ of Pathology and Forensic Medicine, \\ Federal University of Bahia, Salvador, \\ Bahia, Brazi
}

Background: The effect of resveratrol on the management of endometriosis-related pain was investigated in 12 patients who failed to obtain pain relief during use of an oral contraceptive containing drospirenone + ethinylestradiol.

Methods and results: The addition of $30 \mathrm{mg}$ of resveratrol to the contraceptive regimen resulted in a significant reduction in pain scores, with $82 \%$ of patients reporting complete resolution of dysmenorrhea and pelvic pain after 2 months of use. In a separate experiment, aromatase and cyclo-oxygenase- 2 expression were investigated in the endometrial tissue of 42 patients submitted to laparoscopy and hysteroscopy for the management of endometriosis. Sixteen of these patients were using oral contraceptives alone prior to hospital admission, while the remaining 26 were using them in combination with resveratrol. Inhibition of both aromatase and cyclo-oxygenase-2 expression was significantly greater in the eutopic endometrium of patients using combined drospirenone + resveratrol therapy compared with the endometrium of patients using oral contraceptives alone.

Conclusion: These results suggest that resveratrol potentiates the effect of oral contraceptives in the management of endometriosis-associated dysmenorrhea by further decreasing aromatase and cyclo-oxygenase- 2 expression in the endometrium.

Keywords: resveratrol, drospirenone, endometriosis, dysmenorrhea, cyclo-oxygenase-2

\section{Introduction}

Aromatase expression in the eutopic endometrium appears to be crucial not only for the development of endometriosis but also in determining the aggressiveness of the clinical course of this disease. ${ }^{1-4}$ In this respect, drugs that suppress aromatase expression or modulate immunological activity will play an important role in endometriosis therapy. Recent reports have shown the efficacy of aromatase inhibitors in the treatment of aggressive forms of endometriosis when administered in combination with oral contraceptives to patients who previously failed to respond to hormone therapy alone. Resistance to treatment in these cases was associated with high levels of aromatase expression in the endometriotic lesions. ${ }^{5,6}$ The greater efficacy of this combination therapy may be the consequence of a synergism between progestins present in oral contraceptive formulations and aromatase inhibitors. Progestins were found to inhibit aromatase expression in the endometrium by acting at the gene transcription level rather than directly suppressing enzymatic activity, thus enhancing the clinical efficacy of this combination therapy in patients who failed to respond to hormone therapy alone. ${ }^{7-10}$ The isolated use of aromatase inhibitors, on the other hand, is associated with the
CEPARH,

Rua Caetano Moura 35,

402 I0-34I Salvador, Bahia, Brazil

$\mathrm{Tel}+557 \mathrm{I} 32478216$

Email ceparh@uol.com.br 
formation of functional ovarian cysts in premenopausal patients, which limits their use in this group of women. ${ }^{5,6}$

Aromatase expression in the eutopic endometrium plays a crucial role in the clinical course of endometriosis. Previous studies have already shown that the quantity of mRNA transcripts for aromatase is significantly higher in the more aggressive forms of the disease, not only in the lesions but also in the corresponding eutopic endometrium. ${ }^{2,11}$ Whether this could explain the failure of medical therapy with progestins to treat endometriosis in some patients is still speculative; however, higher levels of aromatase activity could counteract the effect of progesterone by augmenting local estradiol production in both the eutopic endometrium and in the endometriotic lesions. ${ }^{2,3,12}$ Nevertheless, the greater efficacy of the combination of an oral contraceptive pill with synthetic aromatase inhibitors for the treatment of endometriosis in patients who fail to respond adequately to hormone therapy alone may suggest that combination therapy with naturally occurring aromatase inhibitors may also be effective, with the advantage of better patient tolerability.

Resveratrol is a polyphenolic compound isolated from the skin of red grapes. At pharmacological doses, resveratrol inhibits aromatase activity at both enzyme and gene transcription levels. ${ }^{13}$ Recent studies have shown that resveratrol is effective in the treatment of endometriosis-induced lesions in nude mice, representing a new alternative for the treatment of endometriosis. ${ }^{14}$ The present study investigated the effect of low doses of resveratrol in the management of endometriosis-related pain in patients who failed to respond adequately to an oral contraceptive pill containing drospirenone + ethinylestradiol given in a continuous regimen. Contraceptive pills containing drospirenone were recently shown to reduce both dysmenorrhea and dyspareunia scores effectively in patients with endometriosis. ${ }^{15}$

\section{Materials and methods}

This open office-based study was conducted to evaluate the effect of resveratrol on the management of endometriosisrelated pain in patients using an oral contraceptive containing drospirenone $3 \mathrm{mg}+$ ethinylestradiol $30 \mu \mathrm{g}$. Twelve patients of reproductive age (range 22-37 years) with a laparoscopic diagnosis of endometriosis, who were still reporting pain and breakthrough bleeding after the first 6 months of use of an oral contraceptive containing drospirenone + ethinylestradiol, were switched to a combination of drospirenone + ethinylestradiol + resveratrol. The symptoms had been present for at least 3 months following initiation of treatment with drospirenone + ethinylestradiol. Resveratrol was obtained from a compounding pharmacy in Salvador, Brazil, and prescribed at a dose of $30 \mathrm{mg} /$ day. The raw material was supplied by Fagron, The Netherlands. The contraceptive pill containing drospirenone was manufactured by Libbs Farmaceutica Ltd, São Paulo, Brazil, and was approved by the Brazilian drug regulatory authorities for use in a continuous regimen under the brand name of Elani $28^{\circledR}$. This office-based clinical study was approved by the internal review board of the Instituto da Mulher, Itaigara Memorial Day Hospital, since neither resveratrol nor Elani 28 are new investigational drugs and both are routinely used in this clinic.

The patients were asked to complete a questionnaire designed to investigate the presence and severity of dysmenorrhea, which was graded in accordance with a 0-3-point multidimensional categorical rating scale modified from that devised by Biberoglu and Behrman ${ }^{16}$ and previously described by other authors. ${ }^{17}$ This scale rates dysmenorrhea according to the reduction experienced in work efficiency and need for bed rest (absence of pain, 0; some loss of work efficiency, mild pain, 1; in bed for part of one day, occasional loss of work, moderate pain, 2; in bed for one or more days, incapacitated, severe pain, 3). All patients graded their dysmenorrhea prior to treatment, during use of the drospirenone + ethinylestradiol contraceptive pill, and following introduction of resveratrol.

In a second group of patients, the effect of drospirenone + ethinylestradiol or drospirenone + ethinylestradiol + resveratrol on aromatase and cyclo-oxygenase-2 (Cox-2) expression in the eutopic endometrium was investigated in 42 patients of reproductive age (range 24-40 years) with pelvic pain and/or infertility submitted to laparoscopy and hysteroscopy not only to confirm the diagnosis of endometriosis but also to treat the lesions. Sixteen of these patients had been using drospirenone + ethinylestradiol in an extended regimen for at least 2 months prior to surgery while the remaining 26 were using the same contraceptive regimen associated with $30 \mathrm{mg}$ of resveratrol. During hysteroscopy, an endometrial biopsy was taken using a Number 5 Karman curette. The tissue was immediately fixed in formalin and sent to pathology. Seven patients in the resveratrol group had been submitted to a pretreatment endometrial biopsy that was tested for aromatase expression and these data were obtained from the patient's medical records. The characteristics of the patients in both arms of this study are shown in Table 1.

Immunohistochemistry was performed following antigen retrieval to detect the presence of aromatase p450 and Cox-2 expression. Aromatase expression was investigated using a 
Table I Characteristics of the patients in both arms of the study

\begin{tabular}{lll}
\hline & $\begin{array}{l}\text { Office-based } \\
\text { study }(\mathbf{n}=\mathbf{~ I 2 ,} \\
\text { mean } \pm \text { SD) }\end{array}$ & $\begin{array}{l}\text { Immunohistochemistry } \\
\text { study }(\mathbf{n}=\mathbf{4 2}, \\
\text { mean } \pm \text { SD) }\end{array}$ \\
\hline Age (years) & $30 \pm 5$ (range 22-37) & $31 \pm 4$ (range 24-40) \\
Parity & $0.2 \pm 0.4$ & $0.1 \pm 0.1$ \\
Body mass index & $28 \pm 4$ & $25 \pm 5$ \\
\hline
\end{tabular}

Abbreviation: SD, standard deviation.

commercially available monoclonal antibody, MCA2077, clone H4 (Serotech, Raleigh, NC), while Cox-2 expression was assessed using CX-294. Antigen retrieval was performed using Tris-ethylenediamine tetra-acetic acid buffer at $\mathrm{pH}$ 8.0. The reaction was revealed using the streptavidinbiotin method. The presence of aromatase expression was rated either as positive if there was any detectable staining reaction in the glandular epithelium or negative when no reaction was observed. Cox-2 expression was graded as 0 when no expression was detected, +1 when there was light staining in more than $10 \%$ of the glands, +2 when staining was moderate, and +3 when Cox -2 was strongly expressed in the endometrium. In all cases, the slides were evaluated by the same pathologist (NP). Placental tissue and a sample of the atrophic endometrium were used as the positive and negative control, respectively, in all immunostaining reactions for aromatase $\mathrm{p} 450$. Tissue sections were stained in one staining run for both Cox-2 and aromatase. Statistical analysis was performed using the Chi-square test to detect differences in percentages, while the Student's $t$-test was used to compare means. Significance was established at $P<0.05$. All patients gave their written informed consent authorizing the immunohistochemical studies to be performed on the endometrial tissue, as determined by the internal review board of the Itaigara Memorial Day Hospital.

\section{Results}

\section{Effect of resveratrol on pain symptoms}

The mean pain score for dysmenorrhea was 3 prior to initiating use of an oral contraceptive pill containing drospirenone in a continuous regimen. After 6 months of use, there was a significant decrease in the pain scores; however, none of the patients reported being completely pain-free since the occurrence of breakthrough bleeding provoked the recommencement of a dysmenorrhea-like pain. The addition of resveratrol to the regimen resulted in a further significant reduction in pain scores after 2 months of treatment, with $82 \%$ of the patients reporting complete resolution of dysmenorrhea and pelvic pain, which was
Table 2 Effect of combination of resveratrol and an oral contraceptive containing drospirenone + ethinylestradiol on dysmenorrhea and pelvic pain scores in patients with endometriosis

\begin{tabular}{lll}
\hline & $\begin{array}{l}\text { Pain score } \\
\text { (mean } \pm \text { SD) }\end{array}$ & $\mathbf{n}$ \\
\hline Baseline & 3 & 12 \\
DRSP/EE & $2.1 \pm 0.5$ & 12 \\
DRSP/EE + resveratrol & $0.2 \pm 0.4$ & 12 \\
\hline
\end{tabular}

Notes: Baseline $\times$ DRSP/EE, $P<0.00$ I; baseline $\times$ DRSP/EE + resveratrol, $P<0.000$; DRSP/EE $\times$ DRSP/EE + resveratrol, $P<0.000$ I (Student's $t$-test).

Abbreviations: DRSP/EE, drospirenone + ethinylestradiol; SD, standard deviation.

associated with an amenorrhea rate of $80 \%$. These results are summarized in Table 2.

\section{Effect of resveratrol on Cox-2 and aromatase expression in eutopic endometrium}

The effect of a previous treatment with an oral contraceptive alone or in association with resveratrol on Cox- 2 and aromatase expression in the eutopic endometrium was investigated in 42 patients submitted to laparoscopy for the treatment of endometriosis. The Cox-2 score in the endometrium was significantly lower in endometriosis patients using the association of drospirenone + ethinylestradiol + resveratrol compared with those using oral contraceptives alone. The median Cox-2 score was 2.5 in the former, but dropped significantly to 1 in those using resveratrol with oral contraceptives. These results are shown in Table 3. In the drospirenone + ethinylestradiol group, none of the women tested negative for Cox-2 expression in the endometrium, while in the resveratrol group $7 / 16$ (43\%) failed to show any staining reaction for Cox-2 (Figure 1).

Aromatase expression was mostly detected in the glandular epithelium; however, some staining was detected in the stroma (Figure 2). In the drospirenone + ethinylestradiol group, 11/16 patients (68\%) still showed a positive reaction for aromatase in the endometrial glands, while in the resveratrol group this percentage was significantly lower. These results are shown in Table 4. In the 7 patients who were

Table 3 Cyclo-oxygenase-2 scores in endometriosis patients using drospirenone+ethinylestradiol or drospirenone+ethinylestradiol+ resveratrol

\begin{tabular}{lll}
\hline & Mean \pm SD & $\mathbf{n}$ \\
\hline DRSP/EE & $2.3 \pm 0.7$ & 16 \\
DRSP/EE + resveratrol & $0.9 \pm 0.8^{*}$ & 26 \\
\hline
\end{tabular}

Note: $* P<0.0001$ (Student's $t$-test).

Abbreviations: DRSP/EE, drospirenone + ethinylestradiol; SD, standard deviation. 

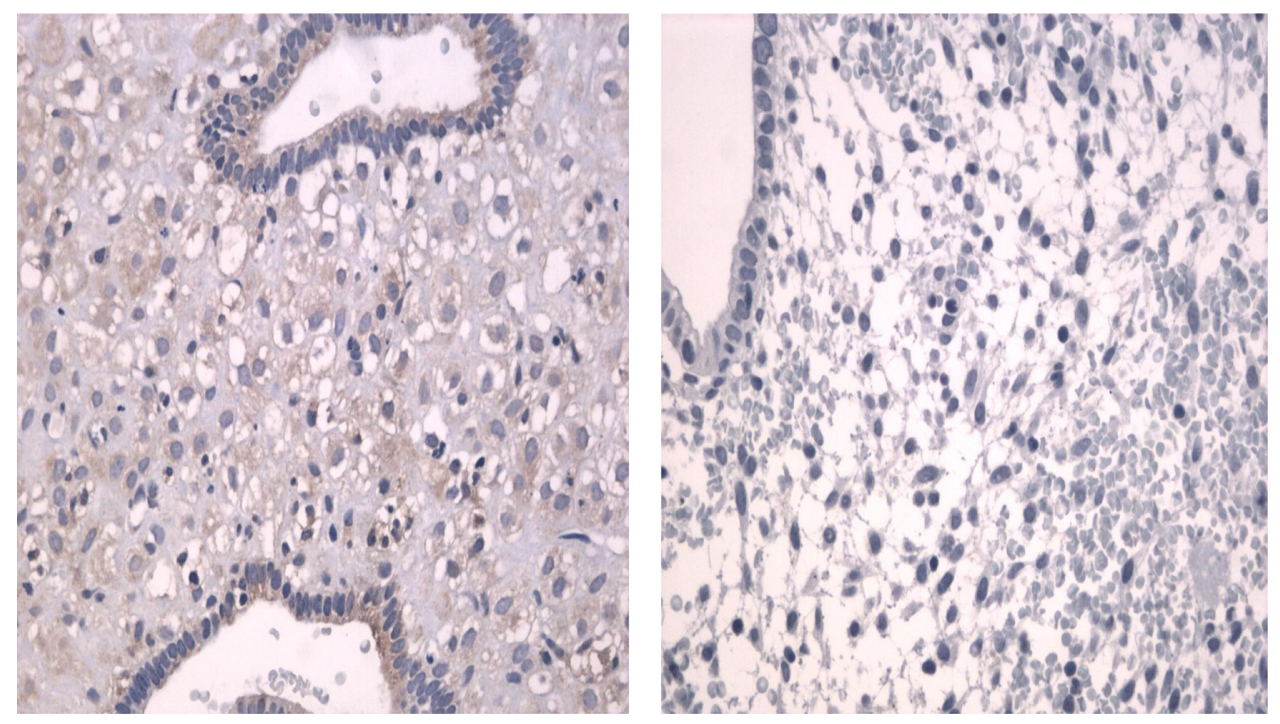

Figure I Cox-2 expression in the glandular epithelium of an endometriosis patient using either drospirenone + ethinylestradiol (left) or drospirenone + ethinylestradiol + resveratrol.

Note: The absence of Cox-2 expression in the patient using resveratrol.

submitted to an endometrial biopsy prior to commencing treatment, the staining reaction for aromatase was positive in all cases; however, the reaction turned negative in 6/7 cases following treatment with drospirenone + ethinylestradiol + resveratrol (Figure 3). Although the patients had different types of lesions including endometriotic cysts, one common feature found during laparoscopy was the remarkably few blood vessels in the lesions (Figure 4).

\section{Discussion}

The present results showed that in endometriosis patients who remained symptomatic while using a continuous regimen of a combined pill containing drospirenone and ethinylestradiol, the concomitant use of resveratrol at a daily dose of $30 \mathrm{mg}$ resulted in a significant reduction in the number of patients reporting the occurrence of pain. This suggests that the combination of oral contraceptives with naturally occurring aromatase inhibitors may show promise for the treatment of endometriosis, particularly in patients who failed to respond satisfactorily to oral contraceptives alone because of the persistence of dysmenorrhea-like pain and breakthrough bleeding. It is important to mention that these symptoms frequently occurred together, consequently highlighting the importance of amenorrhea in the treatment of endometriosis.
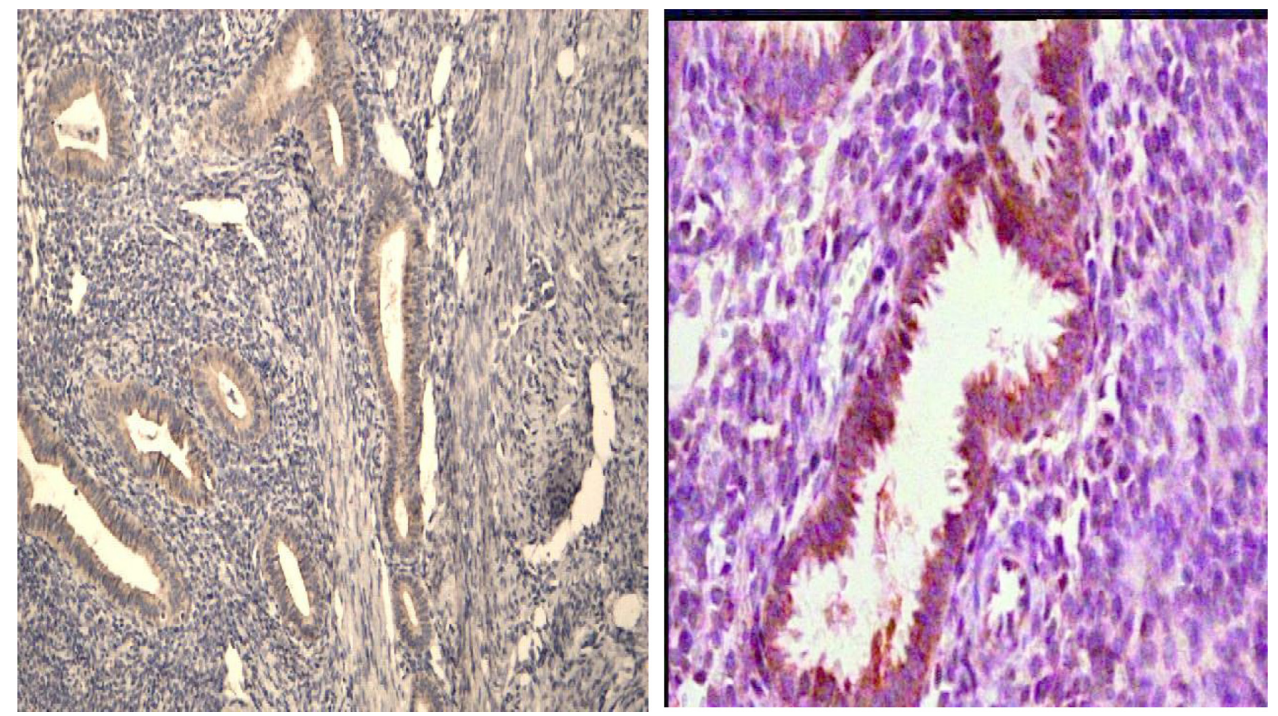

Figure 2 Positive aromatase expression in the glandular epithelium of the endometrium of an endometriosis patient before treatment. 
Table 4 Percentage of endometriosis patients with positive expression for aromatase in the eutopic endometrium

\begin{tabular}{ll}
\hline & Percentage of positive aromatase \\
\hline DRSP/EE & $11 / 16(68 \%)$ \\
DRSP/EE + resveratrol & $5 / 26(19 \%)^{*}$ \\
\hline
\end{tabular}

Note: $* P=0.0013$ (Chi-square test).

Abbreviation: DRSP/EE, drospirenone + ethinylestradiol.

Suppression of aromatase and Cox-2 expression in the eutopic endometrium appears to constitute a necessary prerequisite for the effective control of endometriosisrelated pain, since their persistence in the endometrium was significantly associated with the continuing presence of pelvic pain symptoms and bleeding, as reported in the present paper. In addition to its aromatase inhibiting property, resveratrol has other health promoting effects such as the ability to block the SIRT 1, Cox-2, and transforming growth factor beta genes, characteristics that are not shared by synthetic aromatase inhibitors. ${ }^{18-21}$ In endometriosis, this may exert a positive effect on pain control by curbing down the associated inflammation and fibrosis.

This anti-inflammatory effect of resveratrol is mediated by several mechanisms including the inhibition of nuclear factor kappa beta activation and its translocation to cell nuclei where it will stimulate the transcription of genes connected to the inflammatory cascade. ${ }^{22}$ Although the mechanisms responsible for the increased prostaglandin production in the endometrium of patients with endometriosis are not yet fully understood, estrogens are known to upregulate Cox-2 expression in endometrial stroma cells, thus creating a positive feedback loop between estrogens and the production of proinflammatory prostaglandins such as prostaglandin E2. ${ }^{23}$ Because estrogens may be synthesized locally in the endometrium of endometriosis patients through an enzymatic reaction catalyzed by aromatase, inhibition of this enzyme is probably indispensible for the resolution of dysmenorrhea and other related symptoms. In patients with severe dysmenorrhea but an otherwise normal pelvis at laparoscopy, aromatase expression could already be detected in the endometrium of these patients, thus suggesting that the presence of this enzyme may exacerbate menstrual pain even in the absence of endometriosis., ${ }^{2,3}$

Given that both dysmenorrhea and excessive menstrual bleeding not only depend on Cox-2 expression in the endometrium, but are also frequently associated with symptoms, it is possible that persistent endometrial aromatase expression may contribute to the occurrence of breakthrough bleeding and pain during oral contraceptive use in endometriosis patients by upgrading COX-2 expression in this tissue. ${ }^{23}$ As occurs in primary dysmenorrhea, the locally produced estrogens will promote Cox-2 activity and the ensuing prostaglandin production will provoke uterine bleeding and pain, thus explaining the concomitant manifestation of both symptoms. Because the excess estrogen production in endometriosis takes place locally in the eutopic endometrium and lesions as a consequence of the persistent expression of the aromatase p450 enzyme in these tissues, progesterone resistance may develop as a consequence of this hyperestrogenic milieu. ${ }^{1-3,12}$ This would explain why aromatase expression may still persist in the endometrium of endometriosis patients using oral contraceptives containing drospirenone during the first months of treatment, thus clarifying why pain and breakthrough bleeding still persist
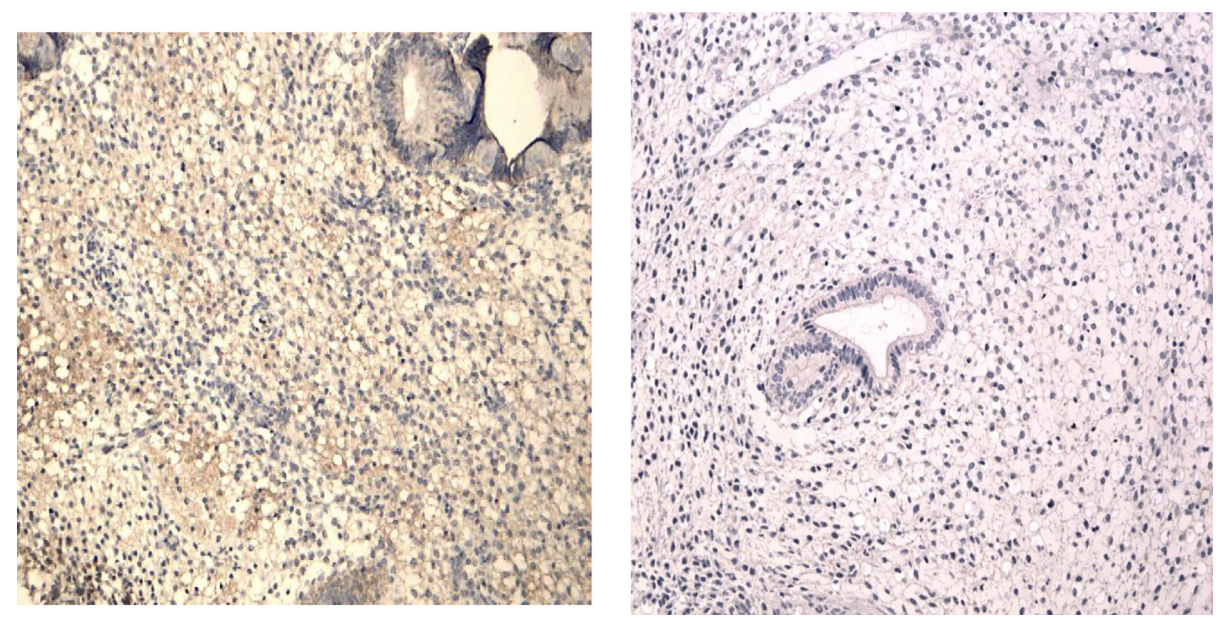

Figure 3 Disappearance of aromatase expression in the eutopic endometrium of an endometriosis patient with the use of drospirenone + ethinylestradiol + resveratrol for 2 months (right).

Note: Aromatase expression was detected in the endometrium of this patient prior to treatment. 


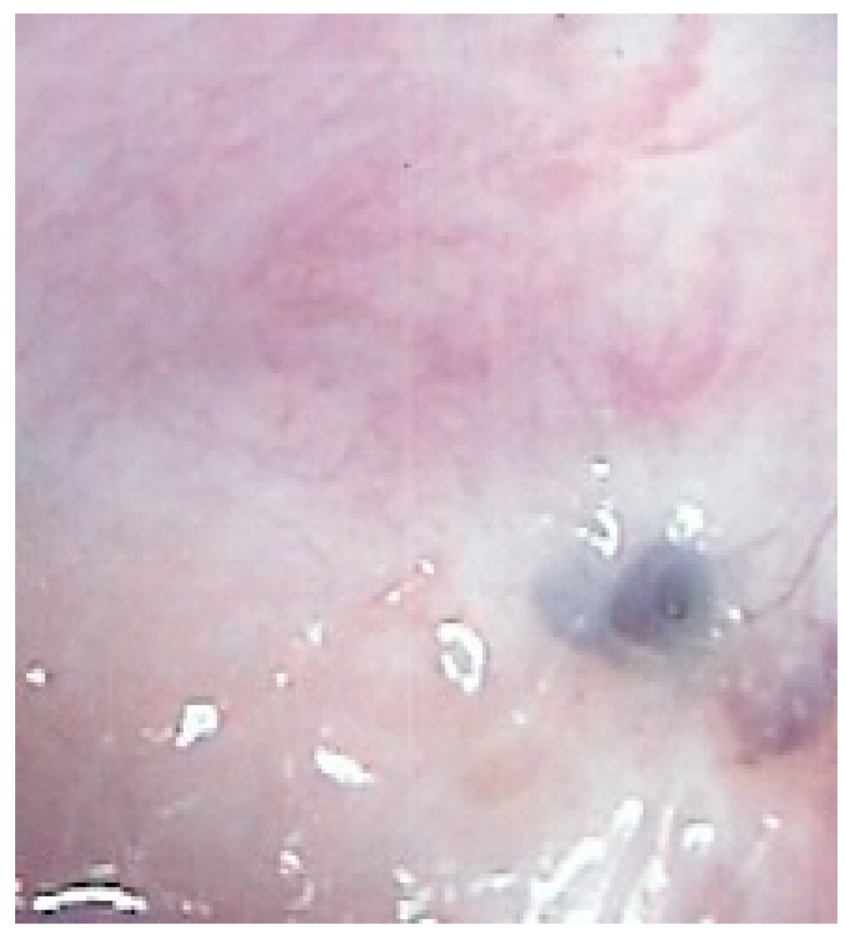

Figure 4 Peritoneal endometriosis lesion in an endometriosis patient using drospirenone + ethinylestradiol + resveratrol.

Note: The few blood vessels in the lesion.

to some extent in these patients despite the continuous use of the medication.

The present results also show that the combination of resveratrol with an oral contraceptive was significantly more successful in reducing the percentage of endometrium with positive expression for Cox-2 and aromatase compared with hormone therapy alone. Previous studies conducted by our group have already shown that breakthrough bleeding in oral contraceptive users is associated with Cox-2 and nuclear factor kappa beta activation, thereby suggesting that the recommencement of inflammation plays a major role in the resumption of uterine bleeding and pain. ${ }^{24}$

In this respect, the anti-inflammatory effect of resveratrol operating through several pathways including the blockade of nuclear factor kappa beta will contribute towards decreasing the pain associated with endometriosis, potentiating the therapeutic effect of drospirenone and rendering the patients pain-free. ${ }^{19-22}$ However, better designed clinical trials are required to provide level 1 evidence that the combination of oral contraceptives with resveratrol is superior to the use of either progestins or combined oral contraceptives alone in the management of endometriosis-related pain symptoms. This is one of the limitations of the present study because it was not designed as a clinical trial to address this question.
Another weakness of the present report is that both aromatase and Cox-2 expression were evaluated only by semiquantitative immunohistochemical methods, with no further confirmatory studies using molecular biology techniques, such as polymerase chain reaction. However, immunohistochemistry is considered to be a valid method in the hands of an experienced pathologist to detect the presence of protein in cells and it is being widely used for that purpose.

\section{Disclosure}

The authors report no conflicts of interest in this work.

\section{References}

1. Attar E. Aromatase and other steroidogenic genes in endometriosis. Translational aspects. Hum Reprod Update. 2006;12:49-56.

2. Maia H Jr, Haddad C, Casoy J. Correlation between aromatase expression in the eutopic endometrium and the presence of endometriosis. Int $J$ Women's Health. 2012;4:61-65.

3. Maia H Jr, Casoy J, Valente Filho J. Is aromatase expression in the endometrium the cause of endometriosis and its related infertility? Gynecol Endocrinol. 2009;25:253.

4. Guo SW. Nuclear factor-kappaB (NF-kappaB): an unsuspected major culprit in the pathogenesis of endometriosis that is still at large? Gynecol Obstet Invest. 2007;63:71-97.

5. Amsterdam LL, Gentry W, Jobanputra S, Wolf M, Rubin SD, Bulun SE. Anastrazole and oral contraceptives: a novel treatment for endometriosis. Fertil Steril. 2005;84:300-304.

6. Bulun SE, Zeitoun KM, Takayama K, Sasano H. Molecular basis for treating endometriosis with aromatase inhibitors. Hum Reprod Update. 2000;6:413-418.

7. Maia H Jr, Casoy J, Correia T, et al. The effects of oral contraceptives on aromatase expression in the eutopic endometrium of patients endometriosis. Gynecol Endocrinol. 2008;24:123-128.

8. Maia H Jr, Casoy J. Non contraceptive health benefits of oral contraceptives. Eur J Contracept Reprod Health Care. 2008;13:17-24.

9. Fechner S, Husen B, Thole H, et al. Expression and regulation of estrogen converting enzymes in ectopic human endometrial tissue. Fertil Steril. 2007;88 Suppl:1029-1038.

10. Yamanak K, Xu B, Suganuma I, et al. Dienogest inhibits aromatase and cyclooxygenase-2 expression and prostaglandin E2 production in human endometriotic stroma cells in spheroid cultures. Fertil Steril. 2012;97:477-482

11. Hatok J, Zubor P, Galo S, et al. Endometrial aromatase mRNA as a possible screening tool for advanced endometriosis and adenomyosis. Gynecol Endocrinol. 2010;27:331-336.

12. Kitawaki J, Kado N, Ishihara H, Koshiba H, Kitaoka Y, Honjo H. Endometriosis: the pathophysiology as estrogen dependent diseases. J Steroid Biochem Mol Biol. 2002;83:149-155.

13. Harikumar KB, Aggarwal BB. Resveratrol: a multitargeted agent for age-associated chronic disease. Cell Cycle. 2008;7:1020-1035.

14. Bruner-Tran KL, Osteen KG, Taylor HS, SokalskaA, Haines K, Duleba AJ. Resveratrol inhibits development of experimental endometriosis in vivo and reduces endometrial stromal cell invasiveness in vitro. Biol Reprod. 2011;84:106-112.

15. Mabrouk M, Solfrini S, Frascà $\mathrm{C}$, et al. A new oral contraceptive regimen for endometriosis management: preliminary experience with 24/4-day drospirenone/ethinylestradiol $3 \mathrm{mg} / 20 \mathrm{mcg}$. Gynecol Endocrinol. 2012;28:451-454.

16. Biberoglu KO, Behrman SJ. Dosage aspects of danazol therapy in endometriosis: short term and long term effectiveness. Am J Obstet Gynecol. 1981;139:645-654. 
17. Vercellini P, Frontino G, De Giorgi O, Aimi G, Zaina B, Crosignani PG. Comparison of a levonorgestrel intrauterine releasing device versus expectant management after conservative surgery for symptomatic endometriosis: a pilot study. Fertil Steril. 2003;80:305-309.

18. Fontein DB, Nortier JW, Liefers GJ, et al. High non-compliance in the use of letrozole after 2.5 years of extended adjuvant endocrine therapy. Results from the IDEAL randomized trial. Eur J Surg Oncol. 2012;38: 110-117.

19. Wang Y, Leung LK. Pharmacological concentration of resveratrol suppresses aromatase in JEG-3 cells. Toxicol Lett. 2007;173: 175-180.

20. Jang M, Pezzuto JM. Cancer chemopreventive activity of resveratrol. Drugs Exp Clin Res. 1999;25:65-77.

21. Shakibaei M, Buhrmann C, Mobasheri A. Resveratrol-mediated SIRT-1 interactions with p300 modulate receptor activator of NFkappaB ligand (RANKL) activation of NF-kappaB signaling and inhibit osteoclastogenesis in bone-derived cells. J Biol Chem. 2011;286: 11492-11505.
22. Ryu J, Ku BM, Lee YK, et al. Resveratrol reduces TNF- $\alpha$-induced U373M human glioma cell invasion through regulating NF- $\kappa B$ activation and uPA/uPAR expression. Anticancer Res. 2011;31:4223-4230.

23. Noble LS. Prostaglandin E2 stimulates aromatase activity in endometriosis derived stromal cells. J Clin Endocrinol Metab. 1997;82: 600-606.

24. Maia H Jr, Casoy J, Correia T. Activation of NF-KappaB and Cox-2 expression is associated with breakthrough bleeding in patients using oral contraceptives in extended regimens. Gynecol Endocrinol. 2010;26: 265-269.
International Journal of Women's Health

\section{Publish your work in this journal}

The International Journal of Women's Health is an international, peerreviewed open-access journal publishing original research, reports, reviews and commentaries on all aspects of women's healthcare including gynecology, obstetrics, and breast cancer. Subject areas include: Chronic conditions (migraine headaches, arthritis, osteoporosis);

\section{Dovepress}

Endocrine and autoimmune syndromes; Sexual and reproductive health; Psychological and psychosocial conditions. The manuscript management system is completely online and includes a very quick and fair peer-review system. Visit http://www.dovepress.com/ testimonials.php to read real quotes from published authors.

Submit your manuscript here: http://www.dovepress.com/international-journal-of-womens-health-journal 